\title{
TURISMO CULTURAL NO CAMPO DE SANTANA E ENTORNO: UM ESTUDO SOBRE A ESTAÇÃO FERROVIÁRIA CENTRAL DO BRASIL NO RIO DE JANEIRO
}

Cultural tourism in Campo de Santana and surrounding area: a study of the Central do Brasil train station in Rio de Janeiro (RJ)

Turismo cultural en Campo de Santana y sus alrededores: un estudio sobre la estación de tren Central do Brasil en Río de Janeiro (RJ)

Carla Conceição Lana Fraga

Universidade Federal do Estado do Rio de Janeiro

(UNIRIO), Brasil

DOI: https://doi.org/10.18472/cvt.20n2.2020.1843

Redalyc: http://www.redalyc.org/articulo.oa?

carlota.fraga@gmail.com $\mathrm{id}=115464354004$

\author{
Eloise Silveira Botelho \\ Universidade Federal do Estado do Rio de Janeiro \\ (UNIRIO),, Brasil \\ eloise.botelho@unirio.br \\ Simone Feigelson Deutsch \\ Universidade Federal do Estado do Rio de Janeiro \\ (UNIRIO), Brasil \\ feigelson@globo.com \\ Vera Lúcia Bogéa Borges \\ Universidade Federal do Estado do Rio de Janeiro \\ (UNIRIO), Brasil \\ vera.borges@unirio.br
}

Recepción: 31 Julio 2020

Aprobación: 21 Agosto 2020

\section{Resumo:}

Nos desafios e oportunidades do patrimônio ferroviário na América Latina no século XXI observa-se que as relações entre memória e patrimônio são chaves. O objetivo foi compreender a interface turismo, cultura e ferrovia relativa à Estação Central do Brasil no contexto do turismo cultural no Campo de Santana e entorno, isto: (a) a partir da tríade história, patrimônio e memória; (b) considerando as conformações da arquitetura e urbanismo para a paisagem urbana. O estudo exploratório e descritivo, foi realizado a partir de levantamento bibliográfico e de dados secundários (online travel reviews - OTRs, disponíveis através do website TripAdvisor). A partir do software QGis foi possível delimitar a área de estudo. A análise textual (Nuvem de Palavras e Análise de Similitude) das OTRs foi realizada através do software Iramuteq. Verificou-se que o entorno da Estação Central do Brasil é relevante para a preservação conjunto do patrimônio cultural, em virtude das singularidades que apresenta para a história, a arquitetura e urbanismo. Os resultados contribuem para a formação de um conhecimento sobre a temática a partir de um olhar sobre o fenômeno turístico e sua interface com a cultura e a ferrovia.

Palavras-chave: Turismo e Patrimônio, Central do Brasil, Campo de Santana.

\section{Abstract:}

Among the challenges and opportunities regarding railroad heritage in Latin America in the twenty-first century, the relations between memory and heritage are keys. The objective was to understand the interface of tourism, culture and railways related to the Central do Brasil Station in the context of cultural tourism in Campo de Santana Park and its surrounding area: (a) based on the history, heritage, memory triad; and (b) considering the architectural and urbanistic conformations of the urban landscape. The study, exploratory and descriptive in nature, was carried out through bibliographic consultation and secondary data from online 
travel reviews (OTRs), available from the TripAdvisor website. The description of the study area relied on the QGis software. The analysis of the texts of the QTRs was performed (Word Clouds and the Similarity Analysis) using the Iramuteq software. It was found that the surroundings of the Central Station of Brazil are relevant for the preservation of the cultural heritage complex, due to the historical, architectural and urban singularities it presents. The results contribute to the construction of knowledge about tourism phenomenon point of view and its interface with culture and the railway.

KeyworDs: Tourism and Heritage, Central do Brasil, Campo de Santana.

\section{ReSUMEN:}

En los desafíos y oportunidades del patrimonio ferroviario en América Latina en el siglo XXI, se observa que las relaciones entre memoria y patrimonio son clave. El objetivo fue comprender la interfaz turística, cultural y ferroviaria relacionada con la Estación Central do Brasil en el contexto del turismo cultural en Campo de Santana y sus alrededores, esto: (a) de la tríada de historia, patrimonio y memoria; (b) considerando las conformaciones de la arquitectura y el urbanismo para el paisaje urbano. El estudio exploratorio y descriptivo se realizó a partir de una encuesta bibliográfica y datos secundarios (revisiones de viajes en línea - OTR, disponibles a través del sitio web de TripAdvisor). Usando el software QGis, fue posible definir el área de estudio. El análisis textual (Word Cloud y Similitude Analysis) de los OTR se realizó utilizando el software Iramuteq. Se encontró que los alrededores de la Estación Central de Brasil son relevantes para la preservación conjunta del patrimonio cultural, debido a las singularidades que presenta para la historia, la arquitectura y el urbanismo. Los resultados contribuyen a la formación de conocimientos sobre el tema a partir de una mirada al fenómeno turístico y su interfaz con la cultura y las vías férreas.

Palabras clave: Turismo y Patrimonio, Central do Brasil, Campo de Santana.

\section{INTRODUÇÃO}

A Estação Ferroviária Central do Brasil, localizada na cidade do Rio de Janeiro, próxima ao Campo de Santana ${ }^{[1]}$, por sua história, é uma das estações ferroviárias mais famosas do país. De acordo com a Supervia (s.d.), operadora de serviços de trens urbanos na região metropolitana (incluindo, além da capital Rio de Janeiro, Duque de Caxias, Nova Iguaçu, Nilópolis, Mesquita, Queimados, São João do Meriti, Belford Roxo, Japeri, Magé, Paracambi e Guapimirim), a relação da referida estação com o Campo de Santana é nítida:

A estação foi inaugurada com o nome de "Estação do Campo" porque a área da estação ficava dentro dos limites do Campo de Santana. Para a sua construção, foi demolida a Igreja de Nossa Senhora de Santana, mas a imagem da santa, em madeira, vinda de Portugal, encontra-se até hoje numa capela na gare da Central (Supervia, s.d.).

Ainda de acordo com a Supervia (s.d.), essa estação também chamou-se “Estação da Corte”, e depois, em homenagem ao Imperador, recebeu o nome de "Estação Dom Pedro II". Já o nome "Estação de Ferro Central do Brasil" data do período republicano, quando ficou chamada como "Estação Central do Brasil". Entre as atrações do local, são citados o Relógio da Central do Brasil, o que faz alusão à arquitetura da Estação, bem como à Capela Nossa Senhora de Santana, o que colabora para se notar a interligação da história desta Estação com a do Campo de Santana, e seu entorno (Supervia, s.d.). Logo, a relação entre os objetos de estudo do turismo está imersa no fato deste ser um fenômeno complexo (Lohmann e Panosso Netto, 2008), ainda mais ao ser tratado em interface com a cultura e a ferrovia (Fraga, 2011). Reconhecendo que o debate em torno do turismo ferroviário pode ser inovado a partir da interdisciplinaridade, levanta-se a seguinte questão: como interpretar as interfaces entre turismo, cultura e ferrovia a partir de um olhar sobre a Estação Ferroviária Central do Brasil e o Campo de Santana? Portanto, o objetivo geral desta pesquisa é compreender a interface turismo, cultura e ferrovia relativa à Estação Ferroviária Central do Brasil no contexto do turismo cultural no Campo de Santana e entorno, isto: (a) a partir da tríade história, patrimônio e memória; e, (b) considerando as conformações da arquitetura e urbanismo para a paisagem urbana.

A pesquisa é exploratória e descritiva, sendo realizada a partir de levantamento bibliográfico com consulta a artigos, livros e websites, bem como a coleta e organização de dados secundários sobre consumer-generated content, isto é o conteúdo gerado por usuário (CGU), notadamente as online travel reviews (OTRs) disponíveis através do website TripAdvisor (2020). Com os avanços da web (1.0, 2.0, 3.0...) nota-se que 
comunidades de consumidores online tem apresentado um papel chave para o que vem sendo conhecido como electronic word-of-mouth (eWOM), ou seja "boca à boca online" (Ferreira, et.al. 2016). Assim, a partir do que está sendo dito nos Online Travel Reviews (OTRs), isto é nas avaliações de destinos, atrações e serviços relacionados a viagem, disponíveis em comunidades virtuais, é possível compreender, mesmo que de maneira indireta, como que as dinâmicas do turismo ocorre frente à um dado "objeto de estudo". A partir do software QGis 3.8 Zanzibar foi possível apresentar a área pesquisada. Para a análise textual (Nuvem de Palavras e Análise de Similitude) das OTRs foi utilizado o software Iramuteq (versão 0.7 alpha 2).

O trabalho está dividido em três seções, além desta Introdução e das Considerações Finais, sendo a próxima sobre turismo, cultural e ferrovia, no qual se faz uma fundamentação teórica sobre história, patrimônio e memória (ver subitem 2.1), arquitetura, urbanismo (ver subitem 2.2.) paisagem urbana (ver subitem 2.3.). A seção 3 é dedicada a explanação sobre as Online Travel Reviews (OTRs) e dos aspectos metodológicos adotados na investigação e a seção 4 é dedicada a apresentação e discussão dos dados. Os resultados podem contribuir para instrumentalizar roteiros-aulas envolvendo a Estação Central do Brasil no contexto do turismo cultural no Campo de Santana e seu entorno.

\section{Turismo, cultura e ferrovia}

O objetivo desta seção é abordar a interface turismo, cultura e ferrovia, sendo que o turismo cultural é entendido como aquele que: (...) implica em experiências positivas do visitante com o patrimônio histórico e cultural e determinados eventos culturais, de modo a favorecer a percepção de seus sentidos e contribuir para sua preservação (...) (Brasil, 2010, p.16). No que tange a ferrovia, observa-se que:

Os transportes ferroviários enquanto uma tecnologia composta por um conjunto de elementos, como via, veículo, força motriz e terminal (PALHARES, 2002), com características próprias, influenciam e são então Instituto Estadual do Patrimônio Cultural - Inepac, criado em 1975, é o herdeiro direto da influenciados por um dado sistema cultural fluido (Fraga e Borges, 2018, p.32).

Assim, nota-se que o turismo cultural que envolve os transportes ferroviários (e, seu conjunto de elementos, ver Palhares, 2002) deve propiciar, a partir destes elementos, uma experiência positiva ao visitante, suscitando a preservação e conservação dos bens ferroviários envolvidos. Logo, ao iluminar a Estação Central do Brasil a partir da tríade história, patrimônio e memória, busca-se compreender de que maneira a arquitetura e urbanismo referidos à esta influencia, ou pode influenciar, na paisagem urbana enquanto objeto do turismo cultural.

\subsection{História, patrimônio e memória}

As aproximações entre história, patrimônio e memória permitem que importantes reflexões sejam produzidas nas últimas décadas. Segundo Choay (2006), a noção de patrimônio no sentido de ligação entre as diferentes temporalidades, isto é, de herança pode ser compreendida pelo lado afetivo que desperta nas sociedades e, também, pela valorização que o transforma em produto de consumo. Na contemporaneidade, o patrimônio histórico e arquitetônico urbano conquista cada vez mais o público mundial provocando culto excessivo a partir de dupla função, isto é, que foca nos bens culturais existentes nas cidades e, também, parece direcionarse para o futuro da sociedade. Entretanto, as diferenças e heterogeneidades existentes no patrimônio parecem não se evidenciar. Nessa discussão, outro conceito importante é a memória a ser interpretada enquanto uma dimensão imaginária da sociedade, um universo mental que permite apreender a questão patrimonial que se apresenta como a materialização de um discurso sobre o passado (Oliveira, 2010).

Em meados do século XIX, a história das ferrovias no Brasil iniciou-se e as primeiras linhas interligam os centros de produção agrícola e de mineração aos portos diretamente e, assim, vencendo obstáculos à 
navegação fluvial. Em 1872, por exemplo, a antiga Estrada de Ferro Oeste de Minas teve a inauguração do percurso que ligava a cidade de Sítio, atual Antônio Carlos, à estrada de Ferro D. Pedro II (Portal IPHAN, 2014). É importante destacar que a principal estação ferroviária representava o novo meio de transporte que ligaria o Rio de Janeiro ao Vale do Paraíba e sua produção cafeeira. Todavia, a sua construção trouxe impactos significativos para a área central da cidade do Rio de Janeiro com a demolição da Igreja Nossa Senhora de Santana, em 1856, tendo em vista a ampliação da ferrovia. Na atualidade, a capela na gare da Central que abriga a imagem em madeira da santa que veio de Portugal pode ser considerada como uma das marcas na memória da destruição da cidade (Portal Brasiliana Fotográfica, s.d.). O patrimônio arquitetônico do século XVIII erguido pela Irmandade de Santana, também formada por negros, ocorreu em função da desavença com a Confraria de São Domingos e, assim, construiu outra igreja (Guia Michelin, 1990). Portanto, naquele momento, as marcas coloniais importantes como a religiosidade e a escravidão foram soterrados pelo arrasamento daquele templo religioso católico motivado pelos avanços da modernidade que pareciam se impor ao Rio de Janeiro. Assim, essa parte da região central carioca perdeu importante elo do seu patrimônio arquitetônico que não pôde ser conhecido pelas gerações que vieram posteriormente e produzindo o esquecimento daquela igreja.

Após a proclamação da República ocorrida em 1889, a ferrovia foi rebatizada como Estrada de Ferro Central do Brasil e, com isso, a estação foi imediatamente chamada de Estação Central do Brasil. Por sua vez, no início dos anos de 1930, o prédio que abrigava a antiga construção também foi demolido em função da expansão do sistema ferroviário, bem como a abertura da Avenida Presidente Vargas. Já em 1943, entre o $21^{\circ}$ e o $26^{\circ}$ andares, o relógio de quatro faces da Central foi inaugurado tendo o formato de quadrado e cada um dos lados com dez metros. Como está montado a 110 metros de altura, as horas são acompanhadas de diversos pontos da cidade (Portal Brasiliana Fotográfica,s.d.). Desde então, o maquinismo que serve para abalizar o tempo e indicar as horas passou a ser uma referência na cidade, e a regularidade de seus ponteiros parecem acompanhar o ritmo das transformações na cidade.

A poucos metros dali, a Praça da República tem ao seu redor muitas instituições públicas (Arquivo Nacional, Casa Histórica de Deodoro, Quartel Central do Corpo de Bombeiros Militar do Estado do Rio de Janeiro e Museu Histórico, Museu da Casa da Moeda do Brasil, Biblioteca Parque Estadual dentre outras) sendo que à época da fundação da cidade, a área era um alagadiço fazendo parte e seus vastos arredores eram denominados Campo da Cidade. Apenas no final do século XIX, o Ministro João Alfredo determinou a transformação do descampado em parque ajardinado com mais de cento e cinquenta metros quadrados, o Campo de Santana. A agitação febril do centro da cidade tem ali um "verdadeiro oásis" com lagos, grutas, chafarizes, estátuas e fauna variada cercada por grades de ferro (Guia Michelin, 1990).

Esta região central carioca serviu de cenário para importantes processos históricos como, por exemplo, em 1841, a coroação de D. Pedro II como imperador do Brasil sendo o local conhecido na época como Campo da Honra e, a seguir, Campo da Aclamação. Além disso, ali a República foi proclamada pelo Marechal Deodoro da Fonseca. Apesar de tantas mudanças de nomes, a localidade nunca deixou de ser chamada de Campo de Santana pela população até os dias de hoje. Como considera Nora (1983), enquanto a memória é a vida e está aberta à dialética da lembrança e da amnésia, a história é a reconstrução problemática do que não mais existe. Enquanto a memória é o lugar do presente eterno e se forma de maneira coletiva, a história é uma representação do passado que se constitui de maneira universal. Nas diferentes temporalidades, o Campo de Santana se constituiu em patrimônio da cidade do Rio de Janeiro marcado pelas tensóes entre história e memória, sendo que a Estação Central do Brasil faz parte de seu entorno. Portanto, a seguir é enfocada a Arquitetura e o Urbanismo. 


\subsection{Arquitetura e urbanismo}

No conjunto das edificações arquitetônicas representativas da paisagem da área central, é importante situar que a Estação Ferroviária e o Campo de Santana são pontos nodais na região, sobretudo no século XIX e no século XX, quando da abertura da Avenida Presidente Vargas (Borde, 2016). Assim, é possível afirmar que esse conjunto urbano e arquitetônico na paisagem local tornam-se pontos de referência no centro do Rio de Janeiro. Do ponto de vista da Arquitetura e Urbanismo, é importante reforçar que a região central da cidade do Rio de Janeiro teve sua paisagem original modificada para a formação do espaço urbano atualmente existente. A formação da cidade se iniciou com a ocupação do antigo Morro do Castelo, demolido. Assim, as áreas da Estação Central do Brasil e do Campo de Santana possuíam a mesma realidade do centro antigo, ou seja, constituíam-se de uma área de mangue que foi drenada para expansão da urbe no século XVIII. O saneamento e as obras realizadas nessa área geraram uma nova superfície para o crescimento urbano quase equivalente à antiga área central já estabelecida. Conforme Cavalcanti (2004, p. 30) essa região encontrava-se:

espremida entre dois pólos: de um lado, a vizinha sesmaria dos jesuítas, bastante próspera,que exercia sua pressão a partir da área hoje correspondente ao bairro de São Cristóvão; de outro, a cidade, que, tendo crescido significativamente, já encostava no manguezal, visto como um entrave a dificultar as constantes travessias da população entre os dois pólos (Cavalcanti, 2004, p.30).

$\mathrm{Na}$ data da chegada da Corte Portuguesa a região em análise já se encontrava parcialmente drenada, com várias vias abertas e um espaço urbano já definido. Em 1808 o local já era conhecido como "Cidade Nova”. Posteriormente, essa área foi urbanizada com a instalação do Campo de Santana, que no início da ocupação era utilizado como pastagem e despejo de resíduos, sendo considerado, no século XVII, como periferia. O parque foi projetado pelo paisagista francês "Auguste Glaziou" e foi inaugurado em 1880, tal como consta no Guia da Arquitetura do Rio de Janeiro (2016). Glaziou projetou um parque nos moldes ingleses, não sendo simétrico e composto de alamedas com grandes áreas gramadas e desníveis, áreas livres e outras sombreadas. O parque conta ainda com cursos d'água, esculturas e elementos em alvenaria que imitam a natureza, característica típica da época de execução, com destaque para a gruta ainda existente no local. No interior da Parque do Campo de Santana encontram-se edificadas a sede da Fundação Parque e Jardins e a Escola Campos Sales (Guia da Arquitetura do Rio De Janeiro, 2016).

Essa área do Campo de Santana e da Estação Central do Brasil é um espaço potencial para abordar sobre fatos e conteúdos da história do país, que estão também expressos nos exemplares da arquitetura brasileira em quase todos os seus períodos de ocupação. É possível dar destaque para as edificações no entorno, conforme consta no Guia da Arquitetura do Rio de Janeiro (2016), entre algumas das construções representativas, os seguintes exemplares: (a) Quartel Central do Corpo de Bombeiros Militar do Estado do Rio de Janeiro dos Bombeiros e Museu Histórico, construção eclética com colunas dóricas de dupla altura, e duas colunas jônicas sob frontão curvo interrompido, além de quatro torres redondas com cúpula metálica; (b) Casa Histórica de Marechal Deodoro ${ }^{[2]}$, que conforme Guia dos Bens Tombados (2001) trata-se de uma edificação assobradada do século XIX em estilo colonial porém com frontaria alterada; (c) Casa da Moeda do Brasil, inaugurada em 1858, e com uso adaptado em 2009 e onde funciona também o Museu Casa da Moeda do Brasil. Construção típica neoclássica, destacando-se a monumental portaria em cantaria com frontão triangular; (d) Arquivo Nacional, onde funcionou a Casa da Moeda do Brasil, construção neoclássica, com acesso por escadaria em cantaria, com colunas e simetria, além de frontões, um frontal e dois nas extremidades finalizado com um coroamento de platibanda, elementos típicos desse estilo; (e) Faculdade Nacional de Direito da Universidade Federal do Rio de Janeiro (UFRJ), construção eclética que foi originalmente construído para fins residenciais e posteriormente ampliada para abrigar o Senado nas fases Imperial e republicana. 
Dentre os exemplares da arquitetura implantados na área tem-se a Estação Central do Brasil construída em 1936/1937 substituindo antiga Estação de Ferro Dom Pedro II construída em 1858. A nova construção desta estação possui estilo Art Déco, com coroamento escalonado, torre e relógio nas quatro faces. De acordo com o Guia da Arquitetura do Rio de Janeiro (2016), o estilo Art Déco tem seu marco inicial na Exposição Internacional de Artes Decorativas e Industriais Modernas em 1925 em Paris. O estilo Art Déco “apresenta um caráter geometrizante e inovador". O Art Déco é considerado um estilo pós-guerra, sendo uma ruptura total com os estilos mais rebuscados e ornamentais do passado, trazendo linhas retas e limpas, coroamento escalonado, edificações mais altas em função da utilização do concreto armado, antes inexistente. O estilo marca o tempo e a velocidade da vida na era industrial. Representado na arquitetura pelas linhas retas e repetitivas, além do uso de elementos geométricos, tais como quadrado, círculo, escalonamento no coroamento da edificação gerando formas aerodinâmicas e muitas vezes, a presença do relógio significando o tempo.

A Estação Ferroviária D. Pedro II, atualmente nomeada de Central do Brasil, conforme Guia dos Bens Tombados da Cidade do Rio de Janeiro (2001) é uma construção tombada pelo processo no 12/001463/92, decreto $\mathrm{n}^{\circ} 14.741$ de 22 de abril 1996, inaugurada em 1943, sendo um projeto do arquiteto Roberto Magno de Carvalho e exame do escritório de Roberto Prenice. Conforme o Guia dos Bens Tombados da Cidade do Rio de Janeiro (2001), a torre principal possui seção quadrada com $135 \mathrm{~m}$ de altura, conferindo o sentido de verticalidade ao conjunto, típico do estilo e possibilita dessa forma a visualização desse marco em vários pontos da cidade, o que implica notar, a partir da arquitetura e o urbanismo, a paisagem urbana como parte das discussões sobre o turismo cultural em seu entorno.

\subsection{Paisagem urbana}

Conforme exposto, a paisagem urbana na qual a Estação Central do Brasil está inserida é constituída por elementos de diversas "camadas históricas". No século XX, uma nova centralidade se ergue, a partir da construção, em frente ao Campo de Santana, da Estação Central do Brasil e do Palácio Duque de Caxias, modificando a paisagem urbana com a introdução de elementos representativos que tendem a traduzir a linguagem de poder do Estado Novo. Estes edifícios foram agregados, conscientemente, no projeto de abertura da Avenida Presidente Vargas, de 1938, conhecido por demolir sobrados, edificações tombadas e amputar parte do parque do Campo de Santana, em nome do "interesse público pautado no progresso" (Sampaio, 2016, p.206). Assim, as alterações urbanas ocorridas nesta região, que marca o ponto mais central do projeto da Avenida Presidente Vargas, instauram ali, não somente novos usos, caracterizado pelo movimento intenso de trens e outros equipamentos viários (Moreira, Bueno, Santiago, 2017), mas contribui também para gerar um debate em torno da noção de patrimônio e paisagem urbanos (Sampaio, 2016).

Em contraste a esta paisagem, em frente à Estação Central do Brasil, na margem oposta da Avenida Presidente Vargas, ganha destaque o parque do Campo de Santana. Esta é a área arborizada mais extensa da região central da cidade do Rio de Janeiro (Fundação Parques e Jardins, 2013). Sua presença contribui para suavizar a paisagem urbana predominada por elementos de concreto e para dar noção de nostalgia ao exprimir "fatos históricos ligados à Pátria e à Humanidade" em meio à costumeiro cotidiano do centro (Dias, Bueno, Acioli, 2015, p.58). Moreira, Bueno e Santiago (2017, p. 213) reforçam esta ideia ao afirmarem que o Campo de Santana constitui elemento marcante, pois reflete uma "transição e conexão entre a moderna avenida e as ruas antigas, remanescentes às modernas intervenções, preferencialmente pedestrianizáveis”.

Este cenário remete à definição de paisagem urbana. Raimundo (2011) afirma que a paisagem é representada pelo modo como diferentes grupos sociais, ao longo de um processo histórico, se organizam em torno de elementos - e suas conexões - materiais (meio físico-biológico) e imateriais (social, econômico e cultural). Segundo Sá Carneiro (2018, p. 7), "a paisagem é uma criação humana, do ser para o mundo e 
do mundo para o ser como uma troca, uma maturação espiritual e física" e de acordo com Paes (2016) as paisagens urbanas são carregadas de uma noção complexa político-ideológica, em que é definido o que será constitutivo de memória coletiva e destinado à conservação, e o que é passível de ser substituído. A paisagem urbana retrata lugares, vivências, história e memória do lugar. Conforme Yázigi (2001, p.34) "ao se pensar na estrutura da personalidade do lugar a paisagem assume especial destaque, pois é precisamente dela que nos chega muito da percepção".

A paisagem adquire uma noção de bem patrimonial ainda na década de 1930, quando da instituição do patrimônio no contexto brasileiro e reforçado, no âmbito internacional, a partir da Convenção da UNESCO para o Patrimônio Mundial, em 1972. Porém, com as transformações da sociedade ao longo do tempo, o entendimento da paisagem como patrimônio ganha complexidade e exige um conjunto maior de instrumentos jurídicos, ambientais e urbanísticos para proteção, refletindo, também, na ampliação do conceito no campo acadêmico. A paisagem possui, portanto, uma complexidade inerente, pois a riqueza e as possibilidades de apropriação conceitual ocorrem em paralelo às características de singularidade e de integração entre natureza e cultura (Ribeiro, 2007).

Os atributos singulares da paisagem cultural expressam a necessidade de proteção e patrimonialização e, podem ser atrativas para o desenvolvimento do turismo cultural em áreas centrais urbanas. Como área de chegadas e partidas, a Estação Central do Brasil constitui espaço público para trânsito de pessoas no cotidiano movimento pendular casa-trabalho, mas também pode ser área para pausa e contemplação, sobretudo quando se aproxima do parque do Campo de Santana. Os elementos da paisagem cultural se constituem em "um dos suportes para a compreensão da histórica paisagem urbana e da memória social da cidade, testemunho de uma época anterior que se adaptou às exigências da modernidade (...)” (Moreira, Bueno, Santiago, 2017, p.213), sendo fundamental para o turismo cultural da cidade do Rio de Janeiro. Assim, o atributo cênico da paisagem urbana adquire significado cultural não somente para a população (Sá Carneiro, 2018), mas também pode oferecer uma experiência singular para o turista (Ellingson, Seidl, Pratt, 2010).

A experiência turística é compreendida como a vivência direta com espaços, lugares e o relacionamento dos sujeitos e, como estes respondem aos estímulos proporcionados pelo ambiente visitado (Pimentel, 2013). Segundo este autor:

a dimensão espacial, assim, parece constituir um elemento da própria essência da experiência turística. Como tal, tem influência decisiva para a qualidade da experiência como um todo, sendo um fator a ser considerado dentro da organização do Turismo promovida pelos agentes públicos e privados (Pimentel, 2013, p.424).

Assim, o turismo cultural é um elemento com potencial para influenciar na constante transformação da paisagem urbana, ao longo de um processo histórico complexo, corroborando para a patrimonialização e ampliando o usufruto coletivo de bens históricos e culturais, notadamente neste estudo os ferroviários. O turismo enquanto um fenômeno complexo que influencia e é influenciado pelos avanços das Novas Tecnologias de Informação e Comunicação, tem na web outras formas de comunicação sobre atrações e destinos que é o conteúdo gerado pelos usuários (CGU). Sendo as Online Travel Reviews (OTRs), isto é avaliações de viagem online relevantes para a compreensão de como as dimensões históricas, arquitetônicas, urbanísticas e paisagísticas de um dado elemento, como é o caso da Estação Ferroviária Central do Brasil se posiciona quando o tema é o turismo cultural no Campo de Santana e seu entorno.

\section{Aspectos metodológicos}

A pesquisa é exploratória e descritiva, sendo realizada a partir de: (a) levantamento bibliográfico para a composição do referencial teórico sobre turismo, cultura e ferrovia nas perspectivas da história, patrimônio e memória; arquitetura e paisagem urbana, bem como online travel reviews expressos na seção anterior; (b) 
coleta e organização de dados secundários sobre OTRs disponíveis através do TripAdvisor (2020) sobre a Estação Central do Brasil.

Para se compreender as dinâmicas (mesmo que indiretamente por dados secundários) que visitantes estabelecem com a Estação Central do Brasil, recorre-se a compreensão do que é o consumer-generated content (CGC), isto é, o conteúdo gerado por usuário, notadamente as Online Travel Reviews (OTRs). Assim, em uma perspectiva filosófica, observa-se que real não se opõe ao virtual Lévy (1996). Com o avanço da web (1.0, 2.0, 3.0, 4.0) (ver Latorre, 2018), a internet conecta cada vez mais pessoas, objetos, lugares. Encurtando distâncias, em muitos casos a partir da ubiquidade inerente às redes wireless (isto é sem fio). Isto fica evidente, a partir das mídias de convergência (ver Jenkins, 2009) e o uso de novas tecnologias de informação (NTICs) com base em aparelhos cada vez menores e mais inteligentes, tal como os smartphones.

É interessante notar que o conteúdo gerado pelo usuário, no caso as OTRs tem uma intenção que se cumpre ou não textualmente, quando a mensagem chega ao seu receptor, no caso a demanda, sendo no turismo, a demanda turística potencial e a real. Nesse sentido, cumpre buscar alternativas para a análise textual. $\mathrm{O}$ software Iramuteq é uma das alternativas, este usa o ambiente estatístico do software R. Foi criado em 2009 por Pierre Ratinaud, sendo gratuito e de código fonte aberto. É licenciado por GNU GPL (v.2) (Salviati, 2017).

No presente estudo, a partir de 65 Online Travel Reviews (OTRs) (isto é n=65) sobre a Estação Central do Brasil disponíveis no website TripAdvisor (2020), foi possível elaborar um corpus textual com o objetivo de analisar a relação desta Estação Ferroviária com o Turismo Cultural no Campo de Santana e seu entorno na cidade do Rio de Janeiro. Embora seja possível fazer outras análises textuais tais como: Diagrama de Zipf, Análise Fatorial de Correspondência (AFC), entre outros, aqui adotou-se metodologicamente duas análises: (a) Nuvem de Palavras e (b) Análise de Similitude.

Isto, pois essas permitem compreender frequências de palavras e ligações entre palavras nos seguintes termos, respectivamente: (a) nuvem de palavras: "(...) É uma análise lexical mais simples, porém, bastante interessante, na medida em que possibilita rápida identificação das palavras-chaves de um corpus (Salviati, 2017, p.79); (b) Análise de similitude "(...) é possível inferir a estrutura de construção do texto e os temas de relativa importância, a partir da coocorrência entre as palavras (...)" (Salviati, 2017, p.69).

Outra opção metodológica adotada foi tratar o conteúdo da OTRs sem focar nos títulos, mas é importante destacar o estudo de Ascaniis e Gretzel (2012). Esses autores analisaram o papel dos títulos da OTRs, e afirmam que essas constituem-se em metadados importantes. Inclusive, do ponto de vista prático podem contribuir para o desenvolvimento de algoritmos para a classificação automatizada de OTRs (Ascaniis e Gretzel, 2012).

A formatação do corpus textual seguiu as indicações de Salviati (2017), sendo que palavras compostas como Rio de Janeiro, Central do Brasil, entre outras foram utilizados o underline para uni-las. Cumpre afirmar também que o dicionário de termos do software Iramuteq apresenta limitações, isto é, palavras que podem não ser reconhecidas (nr), conforme explica Salviati (2017). A seguir são apresentados e discutidos os resultados, relacionando-os com o aporte teórico conceitual tratado na seção 2 sobre turismo, cultura e ferrovia nas perspectivas da história, arquitetura e urbanismo e paisagem urbana.

\section{Resultados e discussões}

Os resultados e discussões são apresentados em duas perspectivas, a primeira da apresentação da área investigada (ver subitem 4.1.) e a segunda sob a perspectiva da análise textual - Nuvem de Palavras e Análise de Similitude sobre a Central do Brasil a partir de 65 OTRs disponíveis através do website TripAdvisor (2020) (ver subitem 4.2.): 


\subsection{Apresentação da área do estudo}

Nota-se que é um território fértil para unir turismo e cultural, pois além das temporalidades históricas e dos estilos arquitetônicos discutidos na seção 2, é possível compreender que a paisagem urbana é conformada por uma pluralidade de espaços tais como aqueles voltados à educação, pesquisa, cultura, religiosidade e entretenimento (ver Figura 1).
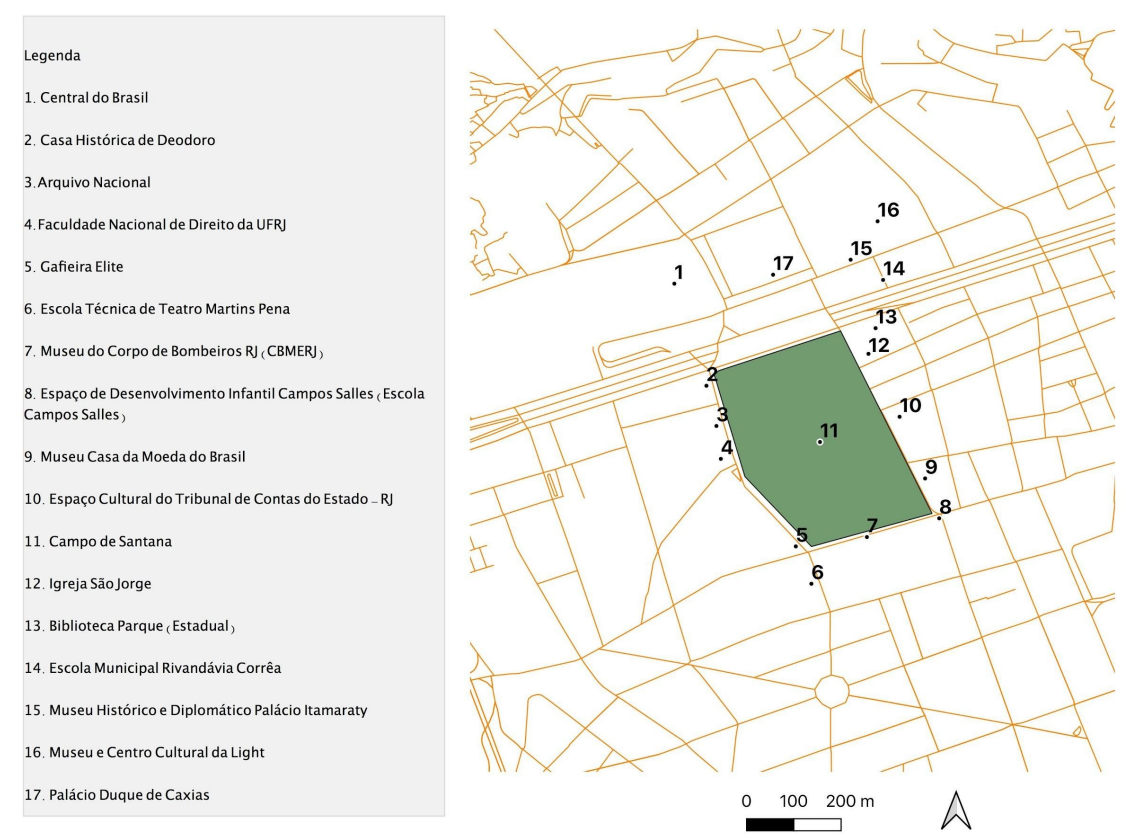

FIGURA 1:

Localização da área do estudo

Elaboração própria com dados da pesquisa, do Data.Rio (2020) e do IBGE Cidades (2017) a partir do QGis 3.8 Zanzibar

Embora exista uma complexidade em se definir totalmente o entorno, e a Figura 1 não esgote este, esta oferece uma nítida visão da centralidade que a Estação Ferroviária Central do Brasil (ponto de número 1 no mapa) e o Campo de Santana (polígono que contém o ponto de número 11 no centro) apresentam na paisagem urbana da qual fazem parte.

Daí, considerando desafios e oportunidades do patrimônio ferroviário na América Latina no século XXI, observa-se que a numeração (por pontos de 1 a 17 da Figura 1) oferece várias possibilidades de itinerários de visitação que a envolver (perpassar, ter início e/ou fim) a Central do Brasil evidenciando sua história, arquitetura e papel na paisagem urbana tanto para moradores, quanto para visitantes, incluindo nisso os turistas. $\mathrm{O}$ que torna tão relevante compreender o que está sendo dito sobre esse patrimônio ferroviário, mesmo que seja através de Online Travel Reviews.

\subsection{Análise textual:}

A seguir são apresentadas as análises textuais (Nuvem de Palavras e Análise de Similitude) a partir das Online Travel Reviews (OTRs) sobre a Central do Brasil. A formatação do corpus textual com as OTRs sobre a Central do Brasil considerou as orientações de Salviati (2017), com especial atenção para a união de palavras utilizando o underline (_), tais como: “Central do Brasil” e "Campo de Santana”. Um dado relevante quanto a frequência é que termos tais como: "estação" e "central" foram relacionados à Estação Ferroviária "Central do Brasil” quando era esse o sentido. No aspecto qualitativo, chama a atenção dois comentários que se referem 
ao filme "Central do Brasil" que tem a referida estação como cenário principal. Esse filme foi protagonizado pela atriz Fernanda Montenegro, que também teve seu nome citado no corpus textual (ver Figura 2). Embora tenha mais de vinte anos desde o seu lançamento, nota-se que esse filme está presente no imaginário de alguns, e talvez isto esteja associado ao fato desta obra cinematográfica ter tido destaque nacional e internacional e ter ganhado prêmios e indicações (CORREIO BRAZILIENSE, 2018).

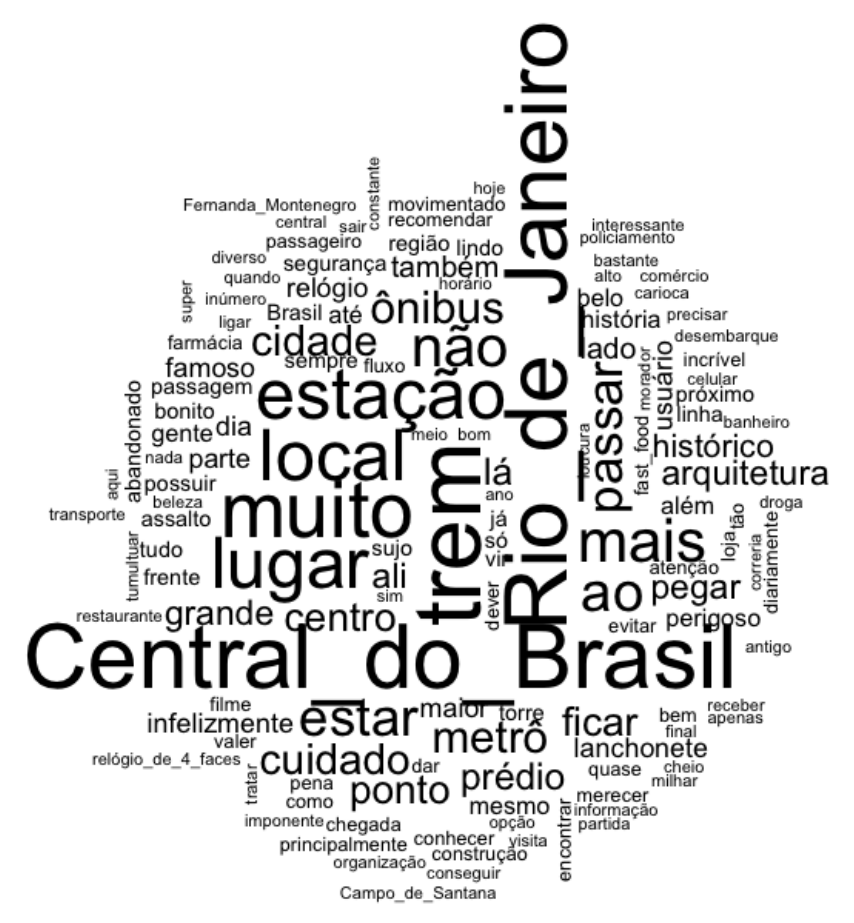

FIGURA 2:

Nuvem de Palavras $(\mathrm{n}=65)$

Elaboração própria a partir do Iramuteq versão 0.7 alpha 2

Outros termos que estão associados à Estação se referem à "torre" e ao "relógio 4 faces". Já Campo de Santana foi referenciado três vezes, contudo expressões tais como: "Parque Campo de Santana" também constam no corpus, demonstrando as relações entre a Central do Brasil e o Campo de Santana na paisagem urbana, da qual ambos fazem parte.

Ainda sobre a Figura 2, é evidente que a palavra "trem" apresenta uma centralidade e que à referência à capital "Rio de Janeiro" (incorporando suas variações, tais como "Rio") também estão presentes nas OTRs analisadas, o que provoca uma associação direta entre a Estação Central do Brasil e o destino turístico Rio de Janeiro. Os vocábulos "histórico" e "arquitetura" também apresentam frequência, o que demonstra a relevância e interseção do referencial teórico abordado para fundamentar a discussão sobre a temática (item 2). A seguir, a Figura 3 apresenta a Análise de Similitude, a partir da qual é possível identificar oito halos com comunidades de palavras, sendo o principal deles iniciado pela palavra "trem", que se liga com "Central do Brasil" e "Rio de Janeiro". 


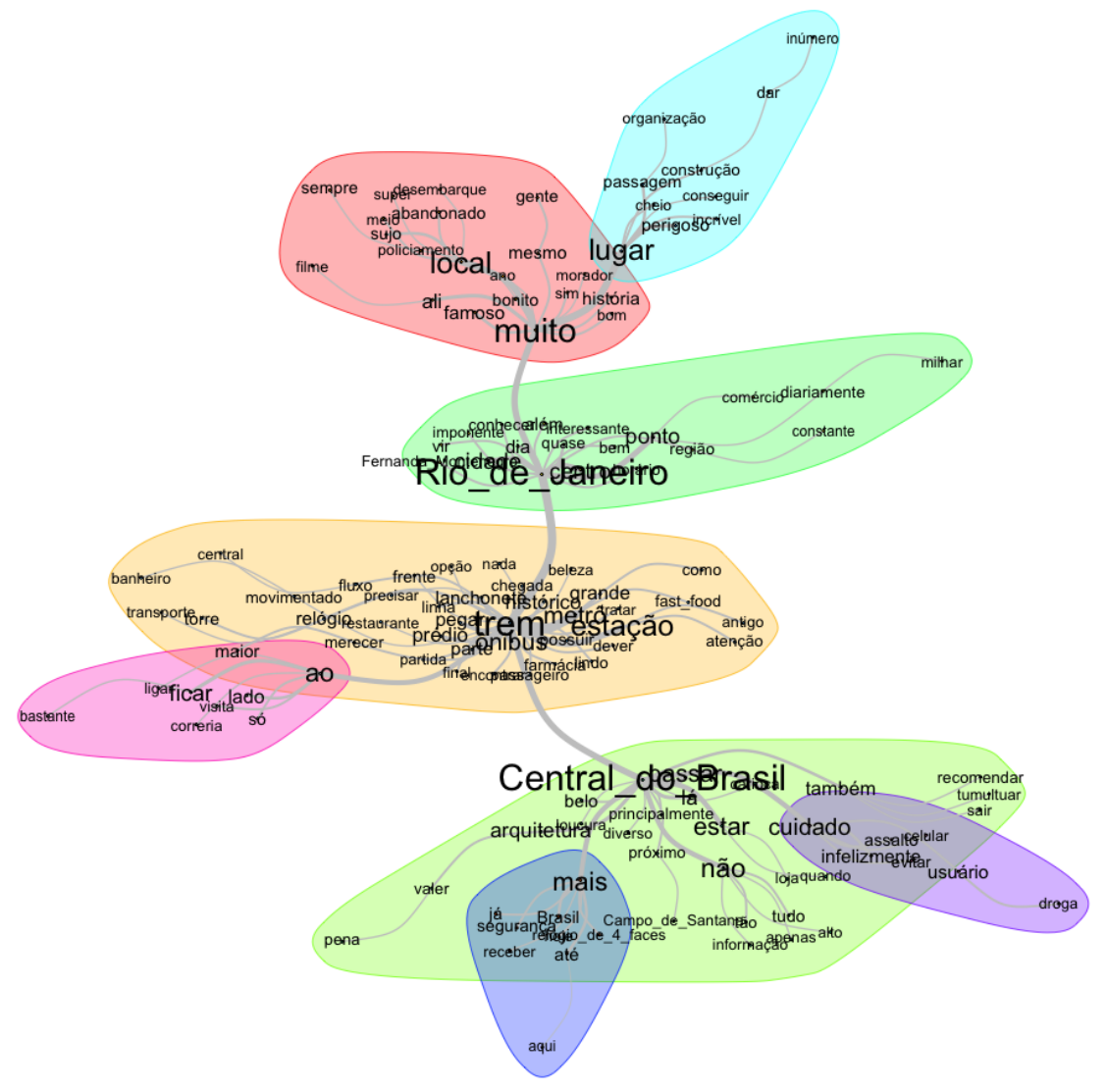

FIGURA 3.

Análise de Similitude ( $\mathrm{n}=65)$

Elaboração própria a partir do Iramuteq versão 0.7 alpha 2

No halo sobre a "Central do Brasil" é possível notar dois outros sub-halos, um relacionado ao termo "mais" e outro relacionado ao termo "cuidado". A partir de uma leitura atenta do corpus textual que serviu a análise feita a partir do software Iramuteq observou-se que a Estação parece ser considerada como "vital" para a cidade, isto por sua capacidade de ligação da região central com diversas zonas e outros municípios, além de abrigar uma série de atributos históricos e arquitetônicos que a torna atrativa para o turismo cultural.

Nesse sentido, embora seja um lugar que apresenta potencial para o turismo por seus signos e significados (notadamente arquitetônicos), ainda parece demandar estratégias de planejamento e gestão coligadas com o seu entorno para que, de fato, aspectos relacionados ao patrimônio, à memória, aos fatos históricos, à arquitetura e urbanismo (ver seções 2.2 e 2.1) contribuam para que a paisagem urbana (ver seção 2.3) da qual faz parte e se posicione como uma atração para o turismo cultural na cidade do Rio de Janeiro (RJ). Um exemplo disso é a relação evidente que se estabelece entre o "Central do Brasil", a palavra "próximo" e "Campo de Santana" no halo "Central do Brasil". Contudo, de acordo com a Figura 1 existe um entorno com várias locais (Casa Histórica de Deodoro, Museu Casa da Moeda do Brasil, entre outros) que não está tão óbvio na análise das OTRs, tendo um grande potencial de articulação através da interface turismo e cultura para que haja visibilidade destes e da Estação Central do Brasil.

A relação que se estabelece entre os halos "Central do Brasil", "trem" e "Rio de Janeiro" demonstra a força que o transporte ferroviário apresenta para o desenvolvimento do "local" e do "lugar" (que fazem parte dos halos interligados ao do "Rio de Janeiro"), e isto é fundamental para que esta estação ferroviária, enquanto patrimônio, configure-se como um elemento chave para o resgate da história e memória ferroviárias num país 
que se tornaram escassas as oportunidades de uso deste modo de transportes para passageiros. Portanto, a educação e a preservação a partir do turismo, caracterizam-se duplamente como desafio e oportunidade, para a visibilidade desse patrimônio ferroviário brasileiro no contexto nacional e internacional.

\section{CONSIDERAÇÕES FINAIS}

Como mencionado, o estudo é exploratório e descritivo e foi realizado a partir de levantamento bibliográfico com consulta a artigos, livros e websites, bem como a coleta e organização de dados secundários sobre o conteúdo gerado por usuário (CGU), notadamente as online travel reviews (OTRs), disponíveis através do website TripAdvisor (2020).

Com o objetivo de compreender a interface turismo, cultura e ferrovia relativa à Estação Ferroviária Central do Brasil no contexto do turismo cultural no Campo de Santana e entorno no Rio de Janeiro (RJ), na segunda seção, ficou evidente a relevância teórica e conceitual da interface entre história, patrimônio e memória para se analisar as conformações da arquitetura e urbanismo para a paisagem urbana. Já na terceira seção, foi possível descrever o papel que a Análise Textual a partir do software Iramuteq, notadamente a Nuvem de Palavras e a Análise de Similitude, a fim de compreender o conteúdo gerado pelo usuário (CGU), neste caso as OTRs.

$\mathrm{Na}$ apresentação e discussão dos resultados é notório como o entorno da Estação Central do Brasil pode e deve ser incluído na lógica de preservação cultural deste território, que é singular por sua história, arquitetura e urbanismo. Sendo que o eletronic word of mouth (eWOM), que é o famoso "boca a boca", por meio eletrônico, a partir da Internet deve ser considerado nas sinergias necessárias ao planejamento e gestão do turismo cultural envolvendo a Central do Brasil, o Campo de Santana e seu entorno no Rio de Janeiro (RJ).

Uma das limitações do estudo foi não ampliar as análises textuais a partir do Diagrama de Zipf, da Análise Fatorial de Correspondência (AFC) e outras análises lexicais. Assim, futuros estudos devem considerar incluir outras análises, pois essas podem oferecer mais panoramas ao objeto de estudo. Por outro lado, novos estudos também devem considerar as limitações do Dicionário de Termos sugeridos por Salviati (2017) e ampliá-lo, sempre que possível. Outra limitação do presente trabalho, é que este tem como foco o estudo sobre turismo, portanto na visão do outro, do visitante e, assim, futuras análises devem considerar o prisma do residente.

Esta e outras pesquisas subsidiarão ainda mais os avanços epistemológicos sobre a temática e ações voltadas aos desafios e oportunidades do patrimônio ferroviário brasileiro no contexto da América Latina no século XXI. Por exemplo, a partir da visibilidade, com ações educativas voltadas à interpretação e à preservação histórica e cultural deste território pelo turismo, será possível fortalecer a relação já existente entre a paisagem urbana da qual a Central do Brasil faz parte e o desenvolvimento do destino turístico Rio de Janeiro.

\section{REFERÊNCIAS}

Ascaniis, S. \& Gretzel, U. (2012). What's a Travel Review Title? In: Fuchs, M. et al. (eds.), Information and Communication Technologies in Tourism Springer.Verlag/Wien.

Brasil. Ministério do Turismo. (2010). Turismo Cultural. orientações básicas. / Ministério do Turismo, Secretaria Nacional de Políticas de Turismo, Departamento de Estruturação, Articulação e Ordenamento Turístico, Coordenação-Geral de Segmentação. 3. ed.- Brasília: Ministério do Turismo.

Brasil. Ministério da Cultura. (2016). Instituto do Patrimônio Histórico e Artístico Nacional. Comunicado. Comunica sobre o tombamento definitivo do Campo de Santana, situado no Municipio do Rio de Janeiro, Estado do Rio de Janeiro. Diário Oficial da União, nº 238, Seção 3. 13/dez/2016. Brasília, DF.

Borde, A. de L. P. (2016) Avenida Presidente Vargas: narrativas históricas Revista do Arquivo Geral da Cidade do Rio de Janeiro. 10 e 11. 
Cavalcanti, N. (2004). O Rio de Janeiro Setecentista, a vida e a construção da cidade da invasão francesa até a chegada da Corte. Editora Zahar.

Choay, F. (2006). A alegoria do patrimônio . UNESP.

Correio Braziliense. Indicado ao Oscar, 'Central do Brasil' completa 20 anos de lançamento. Publicada em 03/03/2018. https://www.correiobraziliense.com.br/app/noticia/diversao-e-arte/2018/03/03/interna_divers ao_arte,670747/20-anos-de-central-do-brasil.shtml.Extraído em 14 de abril de 2020.

DATA.RIO Instituto Pereira Passos (IPP). (2020) Limite Bairro. 2020. Disponível em http://www.data.rio/ datasets/8454eb0454b7424d89c61b67742286a1_15; Recuperado em 15 abril de 2020.

Dias, V., Bueno, A. \& Acioli, J. (2015). Os monumentos do Rio de Janeiro - Inventário. Editora Nau das Letras.

Ellingson, L., Seidl, A. \& Pratt, L. (2010). A route with a view: the contribution of scenic landscapes to a World Heritage Site gateway community. Revista Turismo \& Desenvolvimento (RT\&D), 13/14.

Ferreira, J. B; Angilberto, S. F.; Guaraná, E. R.; Lima, T. V.; Rodrigues, J. W.; Giovannini, C. J. (2016) .O impacto do boca-a-boca online: um estudo sobre a adoção de opiniões em comunidades de consumidores online. TMStudies [online],12(2), 28-37.

Fraga, C. C. L. (2011) Contribuição metodológica para implantação de trens turisticos no Brasil. [Tese de Doutorado, COPPE/UFRJ]. Rio de Janeiro, RJ, Brasil. Site do Programa de Engenharia de Produção (PET). http:// objdig.ufrj.br/60/teses/coppe_d/CarlaConceicaoLanaFraga.pdf. .

Fraga, C.; Borges, V.L. B. (2018). Turismo Ferroviário e de Base Comunitária: algumas conexões para o planejamento e a gestão. Caderno Virtual de Turismo. Dossiê Temático: II Seminário Nacional de Turismo e Cultura da Fundação Casa de Rui Barbosa, 18(1), 28-39. .

Fundação Parques e Jardins (2013). Campo de Santana. Prefeitura Municipal do Rio de Janeiro. Publicado em 28/06/2013. http://www.rio.rj.gov.br/web/fpj/exibeconteudo?id=4203019 Recuperado em 01/abr/2020.

Guia Michelin. (1990) Arturial Editora / Graphos. .

Salomon, M. H. R. et al. (2016). Guia da arquitetura do Rio de Janeiro. Bazar do Tempo.

Telles, A. C. S. (2001). Guia dos Bens Tombados da Cidade do Rio de Janeiro. Expressão Cultura,

INEPAC-RJ (s.d.). Patrimônio Cultural Bens Tombados. Campo de Santana. http://www.inepac.ri.gov.br/index.php/ bens_tombados/detalhar/246>;. Recuperado em 20 abr. 2020.

IBGE (2017). IBGE Cidades. https://cidades.ibge.gov.br Recuperado em 17 abril 2020. (Error 17: El enlace externo https://cidades.ibge.gov.br/> debe ser una URL) (Error 18: La URL https://cidades.ibge.gov.br/> no esta bien escrita)

Jenkins, H. (2009). Cultura da convergência. Editora Aleph.

Lohmann, G.; Panosso Netto, A. (2008). Teoria do Turismo: conceitos, modelos e sistemas. Editora Aleph.

Latorre, M. (2018). História de las Web 1.0, 2.0, 3.0 y 4.0. Universidad Marcelino Champagnat. Marzo. . https:// go.aws/2JA4Yki>; Recuperado em 2 abr. 2020.

Lévy, P. (1996). O que é virtual? Ed.34. .

Leite, D. B.; Souza, P. A. R.; Coco, A. R. M.; Costa, S. R.; Canto, D. S. (2017). O ambiente de gestão de MPEs do setor de turismo no Brasil: uma revisão sistemática. Revista Brasileira de Ecoturismo, 10(1).

Lynch, K. (2006). A imagem da cidade . Editora Martins Fontes.

MHEx/FC. Casa Histórica de Deodoro. Publicado em 29 de Novembro de 2017, 12h32. Última atualização em 31 de Janeiro de 2020, 10h43. http://www.mhexfc.eb.mil.br/pt-br/chdeodoro.html Recuperado em 08 abr. 2020. (Error 19: El enlace externo http://www.mhexfc.eb.mil.br/pt-br/chdeodoro.html> debe ser una URL) (Error 20: La URL http://www.mhexfc.eb.mil.br/pt-br/chdeodoro.html> no esta bien escrita)

Moreira, A.; Bueno, A., Santiago, A. (2017). Paisagem urbana, espaço público e imaginabilidade no eixo monumental da avenida Presidente Vargas, Rio de Janeiro. Paisagem e Ambiente, 39,199-218. https://doi.org/10.11606/ issn.2359-5361.v0i39p199-218. Recuperado em 01/abr/2020.

Nora, P. (1983). Entre memória e história: a problemática dos lugares. Revista História e Cultura. São Paulo, PUC-SP - Programa de Pós-Graduação em História, dezembro. 
Oliveira, E. R. (2010). Memória, História e Patrimônio. Perspectivas Contemporâneas da Pesquisa Histórica. Fronteiras.12(22), jul/dez,131-151.

Paes, M. T. D. (2016). Entre a cultura e a natureza: a patrimonialização das paisagens naturais. In: Irving, M. A.; Calabre, L.; Bartholo, R.; Lima, M. A. G.; Albertino, E. M.; Egrejas, M.; Lima, D. R (Orgs.). Turismo, natureza e cultura: diálogos interdisciplinares e políticas públicas. Fundação Casa de Rui Barbosa. .

Palhares, G. L. (2002). Transportes Turisticos. Aleph.

Pimentel. M. R. (2013). A Experiência Turística e a Imaginabilidade da Paisagem Urbana. Revista Rosa dos Ventos,5(3) 421-438, jul-set.

Portal Brasiliana Fotográfica. Estrada de Ferro Central do Brasil: estação e trilhos. [s.d.] http://brasilianafotografica.b n.br/?p=16093. Recuperado em 23 de março de 2020.

PORTAL IPHAN. (2014). História das Ferrovias no Brasil. http://portal.iphan.gov.br/pagina/detalhes/609 Recuperado em 23 de março de 2020.

Raimundo, S. (2011). Paisagem, turismo e análise ambiental. In: Telles, Reinaldo (Org.). Turismo e meio ambiente. Elsevier. .

Ribeiro, R. W. Paisagem cultural e patrimônio. IPHAN/COPEDOC.

Salviati, M. E. (Março de 2017). Manual do Aplicativo Iramuteq. (versão 0.7 alpha 2 e versão 3.2.3). Planaltina. https:// bit.ly/2UWgkV9. Recuperado em 02/br/2020.

Sampaio, A. R. (2016). Um olhar sobre a história do urbanismo da Área Central do Rio de Janeiro: entre a renovação e a conservação. In: Revista do Arquivo Geral da Cidade do Rio de Janeiro, 10 e 11 . .

Supervia. Central do Brasil. [s.d.] https://www.supervia.com.br/pt-br/estacao/central-do-brasilRecuperado em 04 de fevereiro de 2020. (Error 21: El enlace externo https://www.supervia.com.br/pt-br/estacao/central-do-brasil> debe ser una URL) (Error 22: La URL https://www.supervia.com.br/pt-br/estacao/central-do-brasil> no esta bien escrita)

Yázigi E. (2001). A alma do lugar: Turismo, planejamento, cotidiano. Contexto.

Tripadvisor. Central do Brasil. 2020. https://www.tripadvisor.com.br/Attraction_Review-g303506-d8830195Reviews-Central_do_Brasil-Rio_de_Janeiro_State_of_Rio_de_Janeiro.html Recuperado em 21 de fev. 2020. (Error 23: El enlace externo https://www.tripadvisor.com.br/Attraction_Review-g303506-d8830195Reviews-Central_do_Brasil-Rio_de_Janeiro_State_of_Rio_de_Janeiro.html> debe ser una URL) (Error 24: La URL https://www.tripadvisor.com.br/Attraction_Review-g303506-d8830195-Reviews-Central_do_BrasilRio_de_Janeiro_State_of_Rio_de_Janeiro.html $>$ no esta bien escrita)

Sá Carneiro, A. R. A interação paisagem/jardim na educação do olhar e na conservação do patrimônio. In: Patrimônio e Memória. São Paulo, Unesp, v. 14, n. 1, p. 4-21, jan-jun. 2018.

\section{Notas}

[1] Campo de Santana é o nome que se dá ao espaço público ajardinado no centro da cidade do Rio de Janeiro, tombado pelo Instituto do Patrimônio Histórico e Artístico Nacional (IPHAN) em 2015 (BRASIL, 2016) e pela então Divisão do Patrimônio Histórico e Artístico do Estado da Guanabara - DPHA (atualmente, Instituto Estadual do Patrimônio Cultural - Inepac) em 1968 (INEPAC-RJ, s.d.).

[2] De responsabilidade do Museu Histórico do Exército e Forte de Copacabana (MHEx/FC) (MHEx/FC, 2020). 